\title{
Review of the Anatomy of the Distal Anterior Cerebral Artery and Its Anomalies
}

\author{
Karen CILLIERS, Benedict John PAGE \\ Stellenbosch University, Faculty of Medicine and Health Sciences, Department of Anatomy and Histology, Cape Town, Western Cape, \\ South Africa
}

\section{ABSTRACT}

The anterior cerebral artery (ACA) varies considerably and this complicates the description of the normal anatomy. The segmentation of the ACA is mostly agreed on by different authors, although the relationship of the pericallosal and callosomarginal arteries (CmA) is not agreed upon. The two basic configurations of the ACA are determined by the presence or absence of the CmA.

The diameter, length and origin of the cortical branches have been measured and described by various authors and display great variability. Common anomalies of the ACA include the azygos, bihemispheric, and median anterior cerebral arteries.

A pilot study was done on 19 hemispheres to assess the variation of the branches of the ACA. The most common variations included absence and duplication. The inferior internal parietal artery and the $\mathrm{CmA}$ were most commonly absent and the paracentral lobule artery was the most frequently duplicated (36.8\%). The inferior internal parietal artery originated from the posterior cerebral artery in $40.0 \%$ and this was the most unusual origin observed.

It is important to be aware of the possibility of variations since these variations can have serious clinical implications. The knowledge of these variations can be helpful to clinicians and neurosurgeons. The aim of this article is to review the anatomy and variations of the anterior cerebral artery, as described in the literature. This was also compared to the results from a pilot study.

KEYWORDS: Anterior cerebral artery, Variation, Anomaly, Anatomy, Description, Origin

ABBREVIATIONS: ACA: Anterior cerebral artery, AcoA: Anterior communicating artery, AIFA: Anterior internal frontal artery, CmA: Callosomarginal artery, FpA: Frontopolar artery, IFA: Internal frontal artery, IfO: Infraorbital artery, IIPA: Inferior internal parietal artery, MIFA: Middle internal frontal artery, PIFA: Posterior internal frontal artery, PLA: Paracentral lobule artery, PrcA: Pericallosal artery,

SIPA: Superior internal parietal artery.

\section{INTRODUCTION}

$\mathrm{T}$ The cerebral cortex is primarily supplied by the anterior, middle and posterior cerebral arteries. The anatomy of the anterior cerebral artery (ACA) varies considerably and this complicates the description of the ACA and its branches. The segmentation of the ACA is mostly described similarly by different authors, although the relationship of the pericallosal (PrcA) and callosomarginal arteries $(\mathrm{CmA})$ is not agreed upon (78).

\section{Segmentation}

Various authors have used different terms to describe the segments of the ACA $(36,64,68)$. It can be divided into proximal and distal segments, or pre- and postcommunicating segments. The pericallosal artery is distal to the A1 segment and consists of several segments that can be divided according to its relationship with the corpus callosum. The A2 segment (also referred to as the infracallosal section) runs vertically 
from the anterior communicating artery $(A c o A)$ to the genu of the corpus callosum. The A3 segment (also referred to as the precallosal part) curves around the genu, and the A4 segment (also referred to as the supracallosal section) usually runs in the callosal sulcus and almost reaches the splenium $(3,58$, $62)$. The A5 segment (cortical branches) varies considerably; it is therefore difficult to describe a standard arterial pattern (78). The two basic configurations of the ACA are determined by the presence or absence of the $\operatorname{CmA}(6,58,64)$. The different segments of the ACA are illustrated in Figure 1A, B.

A number of authors only describe three separate segments, namely the $A 1$ segment (also referred to as the horizontal proximal segment or precommunicating part), the A2 segment (vertical proximal segment or postcommunicating part) and the A3 segment (the distal segments and cortical branches) (3). The A2 and A3 segments have collectively been referred to as the ascending (or vertical) segment and the A4 and the A5 segments as the horizontal segment $(62,64)$. The ACA have also been divided into a basal (from the origin to the rostrum of the corpus callosum) and a distal part (runs around genu and above corpus callosum) (62).

Several authors refer to the $\mathrm{A} 1 \mathrm{segment}$ as the anterior cerebral artery and the artery distal to the AcoA as the pericallosal artery $(6,36,62,64,68)$. A few authors have also referred to the $A 1$ and $A 2$ segments as the anterior cerebral artery, and the artery distal to the origin of the callosomarginal artery, the pericallosal artery (62). Since the origin of the callosomarginal artery can vary, this terminology can be problematic (36). The $\mathrm{CmA}$ is also not always present and therefore it is preferable to classify the pericallosal artery as the segment distal to the AcoA $(28,62)$. The callosomarginal artery has been observed in $40.0 \%$ to $93.4 \%$ of specimens $(6,17,28,34,44,54,62,64$, $65,68,69,78)$. The variability of the absence or presence of the $\mathrm{CmA}$ can be due to the different definitions used for this artery (65).

\section{Cortical Branches}

\section{Callosomarginal Artery}

The CmA can be seen as the largest branch of the pericallosal artery (6). The CmA has been defined as the artery that runs near the cingulate sulcus and gives off two or more cortical branches. This definition is problematic since there can occasionally be more than one artery that arises from the pericallosal artery, run in the cingulate sulcus and give rise to a number of cortical branches (78).

Ugur et al. (78) proposed a new classification system. The CmA was either defined as typical, atypical or absent. An atypical $\mathrm{CmA}$ was observed when there was only a very short artery coursing in the cingulate sulcus. Two symmetrical callosomarginal arteries can also be present in the same hemisphere (78). A typical $\mathrm{CmA}$ has a longer course compared to the two symmetrical atypical callosomarginal arteries and usually originates from the A3 segment $(28,62,78)$. Ugur et al. (78) observed typical, atypical or absent CmA's in $49 \%$, $34 \%$ and $17 \%$ respectively.

\section{Infraorbital Artery}

The infraorbital artery (IfO) normally originates from the A2 segment, the callosomarginal artery or as a common trunk with the frontopolar artery $(36,63,68)$. In rare cases the IfO can originate from the A1 segment or from the internal frontal arteries. The infraorbital artery was present in $3.6 \%$ to $100 \%$ of cases $(6,17,34,62,64,68,78)$. Duplication of the IfO have been observed in $6.0 \%$ (64), 39\% (68) and 42\% (78). Ugur et al. (78) observed three and four infraorbital arteries in $16 \%$ and $4 \%$, respectively.
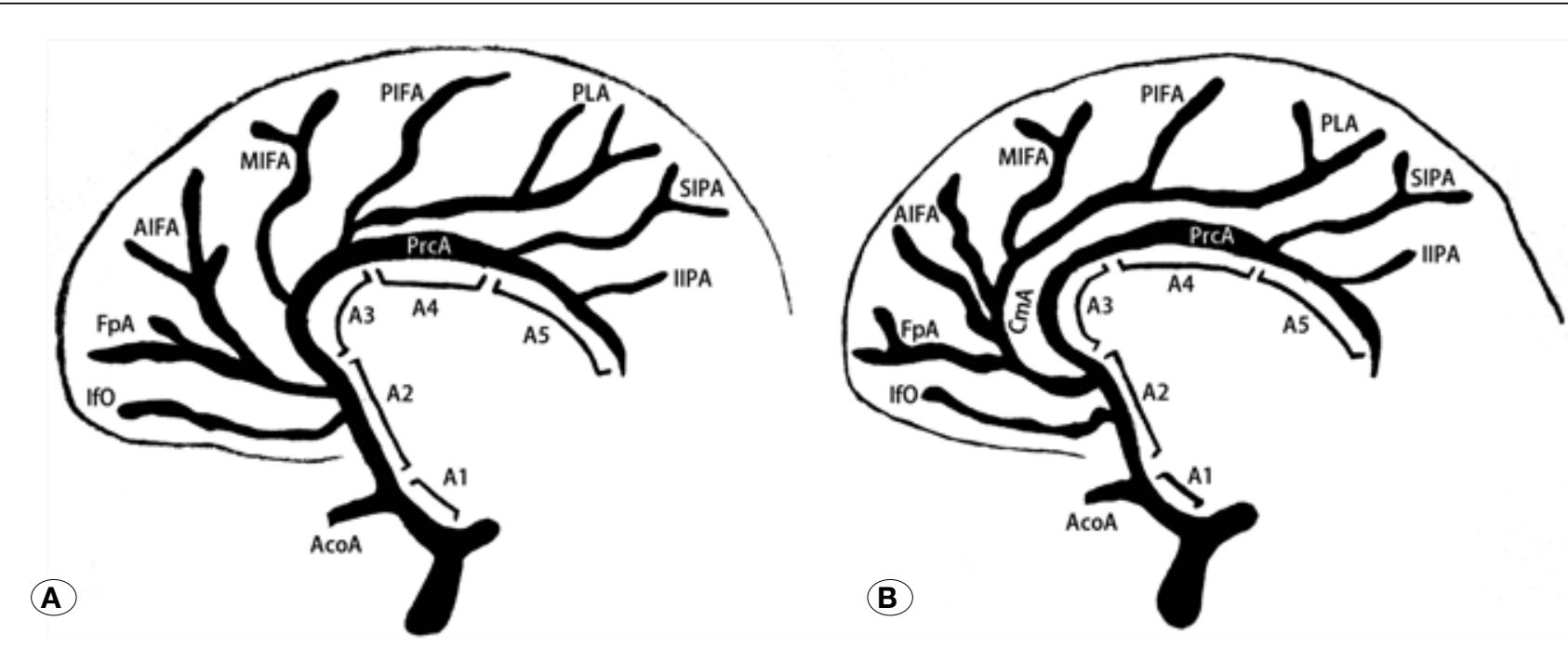

Figure 1: The different configurations of the anterior cerebral artery: A) $\mathrm{CmA}$ is absent, B) $\mathrm{CmA}$ is present. (AcoA) Anterior communicating artery; (AIFA) Anterior internal frontal artery; (CmA) Callosomarginal artery; (FpA) Frontopolar artery; (IfO) Infraorbital artery; (IIPA) Inferior internal parietal artery; (MIFA) Middle internal frontal artery; (PLA) Paracentral lobule artery; (PIFA) Posterior internal frontal artery; (PrcA) Pericallosal artery; and (SIPA) Superior internal parietal artery. 


\section{Frontopolar Artery}

The frontopolar artery ( $\mathrm{FpA})$ usually arises from the $\mathrm{A} 2$ segment or callosomarginal artery $(36,68,78)$. The FpA was present in $12.5 \%$ to $100 \%$ of cases $(6,17,34,62,68,78)$.

\section{Internal Frontal Arteries}

The anterior, middle and posterior internal frontal arteries usually arise separately or in groups of two from the CmA, although the internal frontal branches can occasionally originate from a common trunk, referred to as the internal frontal artery (IFA) (78). Ugur et al. (78) found that the internal frontal artery was present in $58 \%$ of cases. A number of studies $(6,17,28,34,62,68,78)$ observed the anterior internal frontal artery (AIFA) in $33.9 \%$ to $100 \%$ of cases, the middle interal frontal artery (MIFA) in $64.3 \%$ to $100 \%$ of cases and the posterior internal frontal artery (PIFA) in $67.9 \%$ to $100 \%$ of cases.

\section{Paracentral Lobule Artery}

The paracentral lobule artery (PLA) can be viewed as the vessel with the most regular origin, course and area supplied, and was present in $53.6 \%$ to $100 \%$ of cases studied $(6,17$, $34,62,68,78)$.

\section{Internal Parietal Arteries}

The superior internal parietal artery normally originates from the A4 segment and runs to the precuneus (36). Ugur et al. (78) found that the superior internal parietal artery (SIPA) can also arise from the callosomarginal artery or the paracentral lobule artery. The inferior internal parietal artery (IIPA) originates from the A5 segment and runs to the lower third of the precuneus (36). A number of studies $(17,28,34,62,68,78)$ observed the SIPA in $78 \%$ to $100 \%$ of cases and the IIPA was present in $60 \%$ to $85 \%$ of cases observed.

\section{Anomalies and Variations}

The abnormalities of the distal ACA have been divided into three major groups (Figure 2A-D) namely; azygos ACA, bihemispheric ACA and a median anterior cerebral artery. Other variations include complete absence of a pericallosal artery and four pericallosal vessels $(25,59)$. Ozaki et al. (59) described one case $(0.7 \%)$ of duplication of the ACA bilaterally (four pericallosal vessels). Ladziński et al. (39) observed an extra ACA branch that originated from the internal carotid artery. Burbank and Morris (4) observed a left ACA arising from the right internal carotid artery and noted that only one other case has been observed in the literature.

\section{Azygos Anterior Cerebral Artery}

The azygos ACA (Figure 2A-D) is formed by the fusion of the two A2 segments and runs into the medial surface of the hemispheres and usually divides below the genu to supply both hemispheres $(4,6,9-11,17,21,25,28,32,34,36,39$, 42 , 44, 49, 54, 57, 59, 60, 62, 63, 65, 69, 78). The azygos ACA can also be formed when the embryonic median artery persists (60).

The azygos ACA usually has little clinical significance (57) although this variation may be associated with other anomalies including agenesis of the corpus callosum, formation of arteriovenous malformations and ischemia $(18,24)$. Some authors state that aneurysms are frequently associated with an azygos ACA $(9,85)$, whereas others state that this association is extremely rare $(35,82)$. Since this artery supplies parts of both hemispheres, occlusion may result in a large ischemic area $(9,31,57)$. The azygos ACA have been observed in $0.1 \%$ to $11.6 \%(1,2,12,14,17,18,20,30,43,45,51,54,67,68$, $74,76,78,82,83,85)$ of cases studied.

The degree of fusion between the left and right ACA can vary from minor contact to a long single trunk $(52,70)$. Kapoor et al. (30) found that the trunk could be joined for $0.5 \mathrm{~cm}$ to $4 \mathrm{~cm}$. When the arteries are connected for a shorter length, the variation can also be termed long fusion. Vasovic (80) observed an azygos ACA that was fused for $3.3 \mathrm{~mm}$ and then divided into three arteries, the right and left A2 segments and a median anterior cerebral artery.

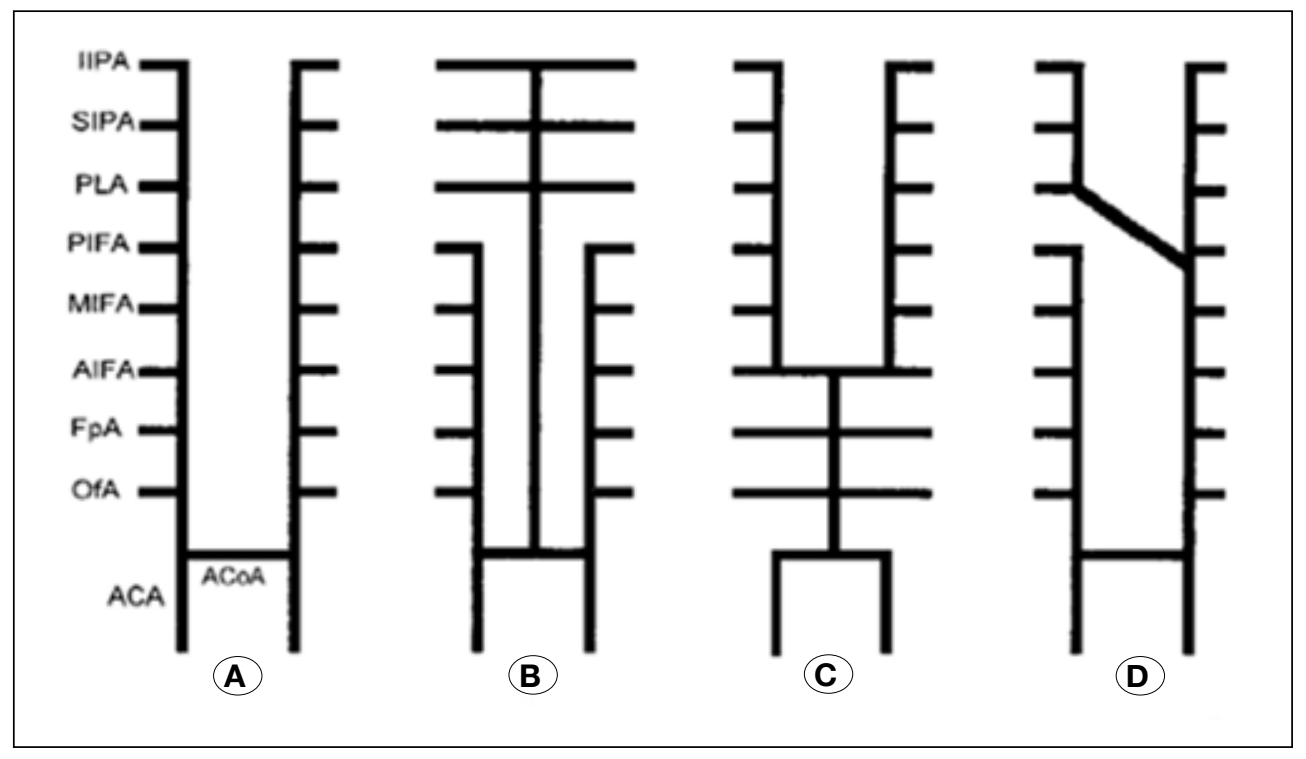

Figure 2: The different patterns of the anterior cerebral artery (68). A) Normal pattern, B) Median anterior cerebral artery, C) Azygos ACA, and D) Bihemispheric ACA. 
Gunnal et al. (18) divided the azygos ACA into five subgroups (Figure 3). Type I is the classic or true azygos ACA while Type II consists of a shorter stem. In Type III there are two A2 segments, although one terminates early. In Type IV there are two A2 segments, although one terminates as the callosomarginal artery. Type $\mathrm{V}$ is the median anterior cerebral artery (18). Gunnal et al. (18) observed these five types in $2.7 \%, 1.8 \%, 3.6 \%, 2.7 \%$ and $0.9 \%$ respectively. The azygos ACA should not be confused with the bihemispheric ACA (classified as Type III and Type IV) $(31,73,76)$.

The classic or true azygos anterior cerebral artery (Type I) can be described as an artery that does not divide into two distal ACA and gives rise to all cortical branches of both hemispheres. The azygos ACA usually divides close to the genu (Type II) into two pericallosal arteries to supply both hemispheres (18). This variation is more commonly observed compared to the true azygos ACA (21).

\section{Bihemispheric Anterior Cerebral Artery}

A bihemispheric ACA is defined when one A2 segment is hypoplastic (or terminates early) and the contralateral artery divides to supply both hemispheres $(3,11,42,57,60,62,64)$. A bihemispheric ACA was present in $0.2 \%$ to $8.0 \%(20,34,62$, $64,65,69$, ) of specimens cited in the literature.

\section{Median Anterior Cerebral Artery}

When the median ACA is observed, a third distal ACA is present and can branch to the distal medial surface of one or both hemispheres $(11,30,36,52,60,61,68)$. The median ACA usually curves around the genu and ends at the level of the body of the corpus callosum (26). The cause of this variation is unknown although this artery can be the result of the persistent or patent development of the median artery of corpus callosum, possibly due to a hypoplastic ACA $(11,57$, 61).

The median anterior cerebral artery usually originates from the AcoA $(10,13,21,46,57,61,74)$. In the literature the median ACA originated from the AcoA in $87 \%$ (30), 90\% (26) and 100\% $(28,34,37,59,65,75,83)$ of cases. The artery can additionally originate from the junction of the $\mathrm{A} 1$ and $\mathrm{A} 2$ segments in $10 \%$
(26) and $13 \%(30)$ of cases. A median ACA was present in $1.0 \%$ to $35.0 \%(1,8,12,13,17,26,28,30,33,34,37,38,45$, $47,51,53,56,59,65,67-69,71,74-76,83,85)$ of cases by previous authors. The average diameter of the median ACA has been measured to be $0.9 \mathrm{~mm}(75)$ and $1.28 \mathrm{~mm}$ (26).

\section{Supreme Anterior Communicating Artery}

This junction can also be termed the superior anterior communicating artery (23). There is an additional connection between the right and left $A 2$ segments above the AcoA $(18,41)$. Laitinen and Snellman (41) observed this variation between the two pericallosal bifurcations. This variation has been observed in $20 \%$ (23) and $21.4 \%$ (41) of cases in the literature.

\section{Fenestration}

Fenestration occurs when the lumen of an artery is divided into two segments. It can also be referred to as partial duplication $(2,5,16,60,72)$. Both segments have an endothelium and muscular layer although the adventitia can be shared (60). There are two types of fenestrations; small slit-like and large convex-like fenestrations. The small slit-like fenestration is the most common type (77).

These incomplete duplications are usually present in the vertebrobasilar region although it has been observed in the cerebral arteries $(2,19,55,60,77)$. The weakness of the wall of the fenestration and hemodynamic stress at these locations can play a role in aneurysm formation (76).

Fenestrations of the ACA usually occur at the distal part of $A 1$ segment (76) specifically, the distal half or two-thirds of the A1 segment $(7,48,50)$. Most authors do not specify which part of the A1 segment the fenestration was observed. Ito et al. (22) stated that in all three cases the fenestration was located at the medial half of the A1 segment while Yamada et al. (84) also observed a fenestration at the middle part of the A1 segment. The cause is unknown although these fenestrations may be remnants of a plexiform anastomosis (57). Fenestrations of the ACA have been observed in the literature in $0.1 \%$ to $4.9 \%$ $(30,59,66,76,79)$ of cases previously studied.

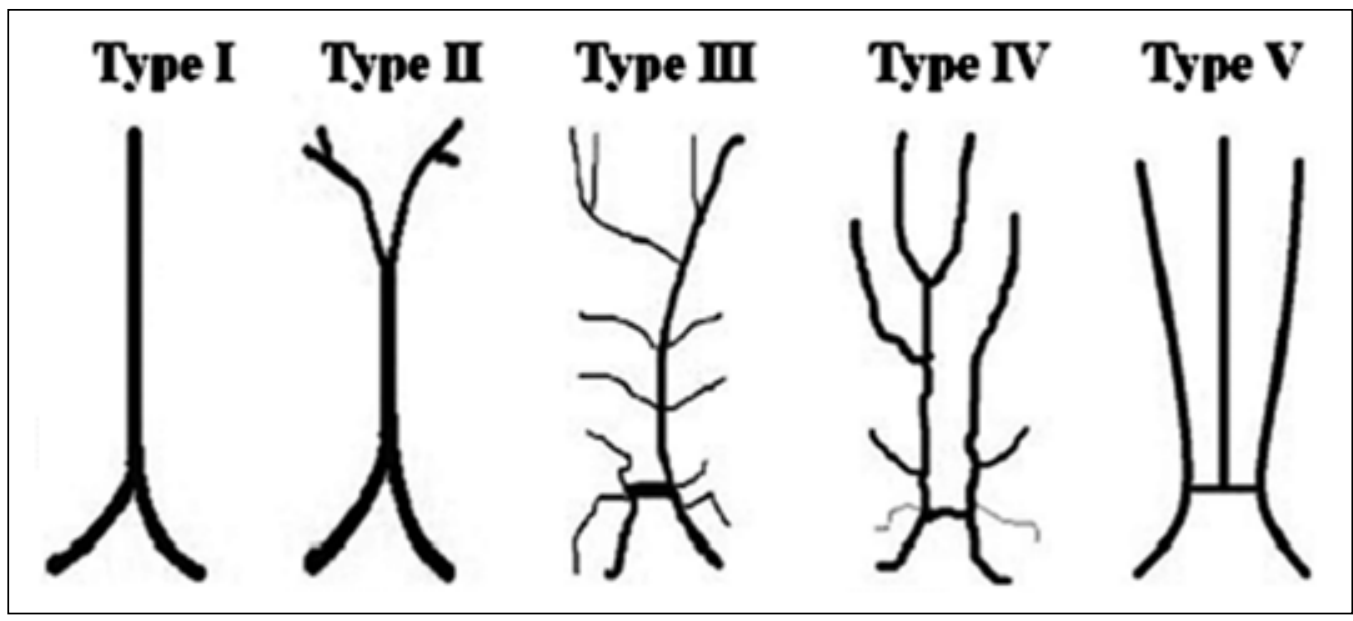

Figure 3: Four different types of an azygos anterior cerebral artery and the median anterior cerebral artery (18). 
Very few authors specified if the fenestrations were small slit-like or large convex-like. Large convex-like fenestrations were observed in $1.0 \%$ and smaller slit-like fenestrations were observed in $0.2 \%$ of cases by Uchino et al. (76). Fenestrations of the ACA on both sides are extremely rare (22), although Friedlander and Oglivy (15) and Vucetić (81) reported bilateral fenestration of the $\mathrm{A} 1$ segment.

\section{Pilot Study}

A pilot study was done on 19 hemispheres to assess the anatomy of the ACA and its branches. The anterior cerebral arteries were injected with an isotonic saline solution to remove any blood or blood clots and were then injected with a coloured silicone. After perfusion the specimens were fixed in $10 \%$ buffered formaldehyde for at least two weeks. The external diameter was measured using a digital micrometre and the length was measured using string and a ruler.

The most common variations were complete absence of an artery and duplication. The infraorbital artery and the FpA

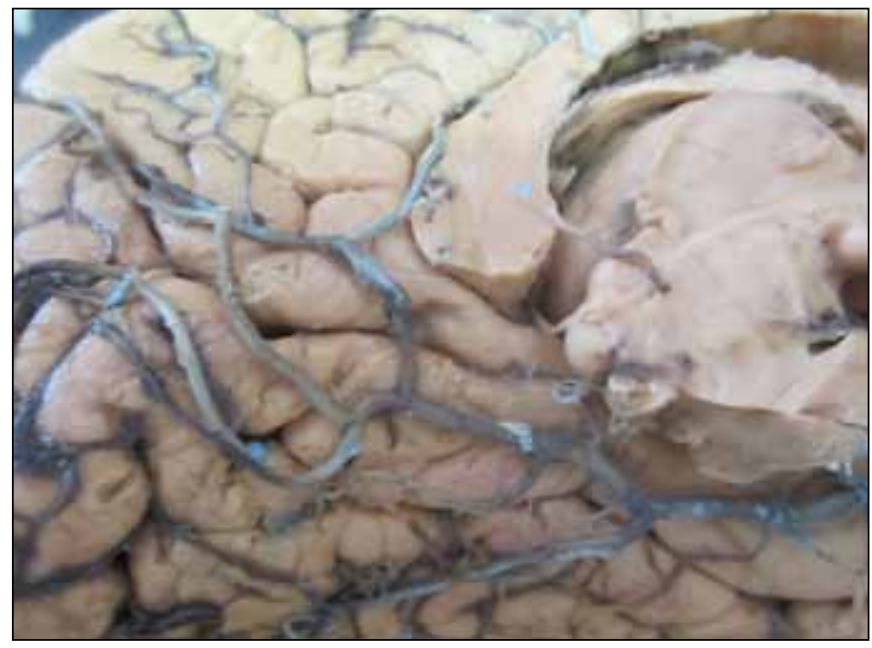

Figure 4: The inferior internal parietal artery originating from the posterior cerebral artery. were absent in $42.1 \%$ and $47.4 \%$ of cases respectively. The anterior, middle and posterior internal frontal arteries were always present, although the AIFA and PIFA were duplicated in one case each. The MIFA was the most consistent artery, since it was always present and was never duplicated. The paracentral lobule artery was the most frequently duplicated and this was observed in $36.8 \%$ of cases. The superior and inferior internal parietal arteries were absent in $10.5 \%$ and $26.3 \%$ respectively and the IIPA was duplicated in one case. The callosomarginal artery and the IFA were observed in only $31.6 \%$ of cases in the pilot study. The callosomarginal artery and IFA were only present in the same hemisphere in one case.

The diameter, length and origin of the cortical branches of the ACA have been measured previously in the literature and this is depicted in Table I to Table IV. The data from the pilot study are tabulated in Table $\mathrm{V}$. The diameters are measured at the origin of the cortical branch and the length is measured from the origin of the artery to the AcoA.

Knowledge of the course, length and curvature of the arteries is vital for treatment of pathologies. Variation of the length is important in neurosurgical procedures since a shorter trunk may play a role in aneurysm formation. Changes in vessel diameter could also indicate early signs of several pathological conditions (85).

The most notable origin was the IIPA originating from the posterior cerebral artery in $40.0 \%$ (Figure 4). This is a rare variation although Ladziński and Maliszewski (40) observed the inferior and superior internal parietal arteries arising from the posterior cerebral artery in one case (1.1\%), and the IIPA arising from the posterior cerebral artery in five cases (5.3\%).

The average diameters of the branches are similar to the results of Ugur et al. (78), Stefani et al. (68) and Perlmutter and Rhoton (62). The IIPA originated from the posterior cerebral artery in six cases, resulting in a much shorter length compared to when the IIPA originated from the anterior cerebral artery.

The differences of measured length between studies show that there might be marked difference between populations

Table I: The Average Diameter $(\mathrm{mm})$ at the Origin of the Arteries and the Average Length ( $\mathrm{mm})$

\begin{tabular}{|c|c|c|c|c|c|c|c|c|c|c|}
\hline Diameter & IfO & FpA & CmA & IFA & AIFA & MIFA & PIFA & PLA & SIPA & IIPA \\
\hline Perlmutter and Rhoton (1978) & 0.9 & 1.3 & 1.8 & - & 1.3 & 1.3 & 1.4 & 1.3 & 1.2 & 1.1 \\
\hline Stefani et al. (2000) & 0.9 & 1.1 & 1.8 & - & 1.3 & 1.4 & 1.3 & 1.2 & 1.0 & 0.8 \\
\hline Ugur et al. (2006) & 1.1 & 1.4 & 1.9 & 1.7 & 1.3 & 1.2 & 1.3 & 1.4 & 1.3 & 1.2 \\
\hline Kedia et al. (2013) & 0.2 & 0.5 & 1.1 & - & 0.4 & 0.4 & 0.3 & 0.3 & 0.3 & 0.2 \\
\hline Length & IfO & FpA & CmA & IFA & AIFA & MIFA & PIFA & PLA & SIPA & IIPA \\
\hline Perlmutter and Rhoton (1978) & 5.0 & 14.0 & 43.0 & - & 47.0 & 65.0 & 73.0 & 79.0 & 92.0 & 131.0 \\
\hline Stefani et al. (2000) & 7.7 & 21.6 & 29.4 & - & 41.3 & 56.8 & 70.3 & 84.8 & 101.6 & 112.6 \\
\hline
\end{tabular}


Table II: The Origins of the Infraorbital, Frontopolar and Callosomarginal Arteries

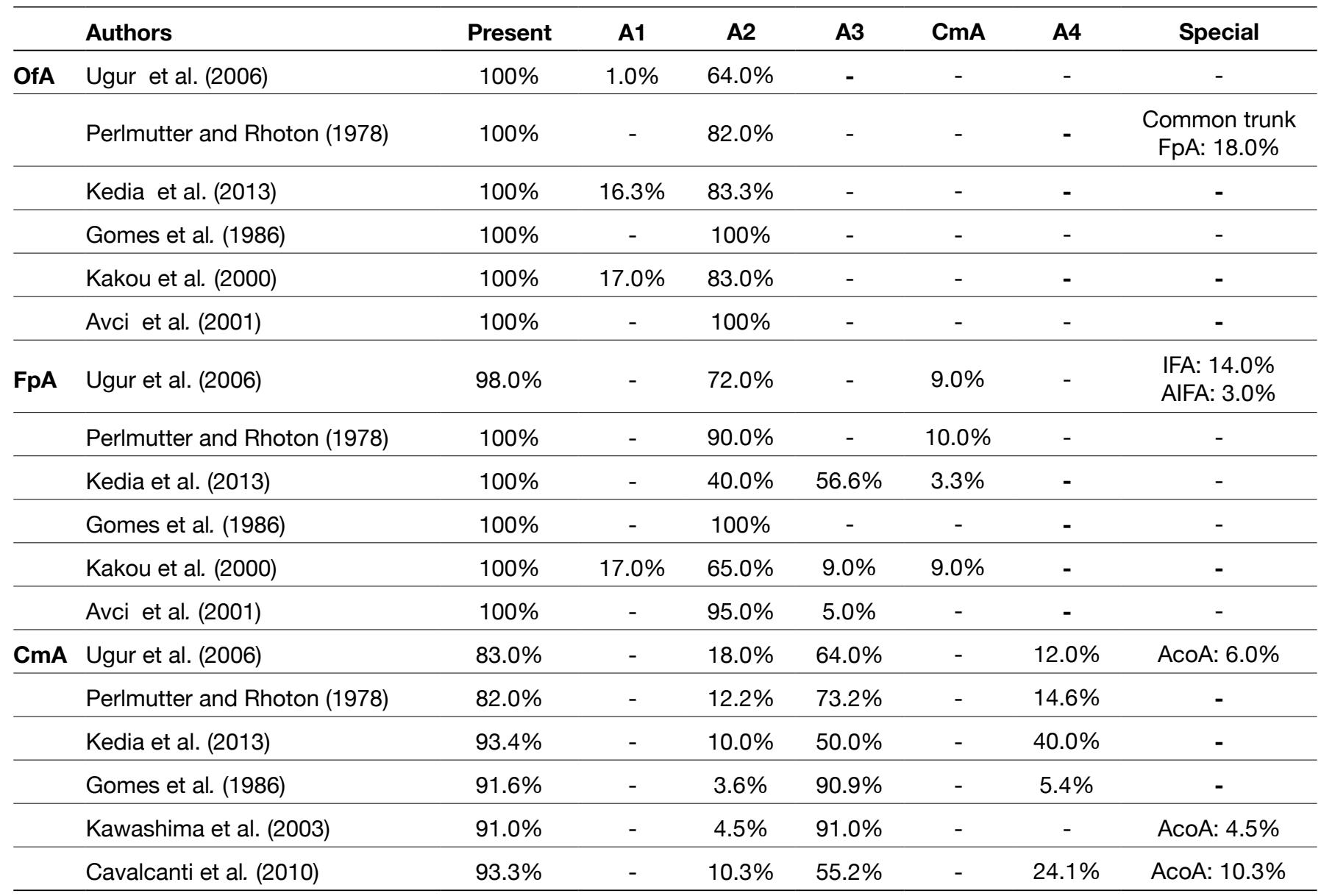

Table III: The Origins of the Anterior, Middle and Posterior Internal Frontal Arteries

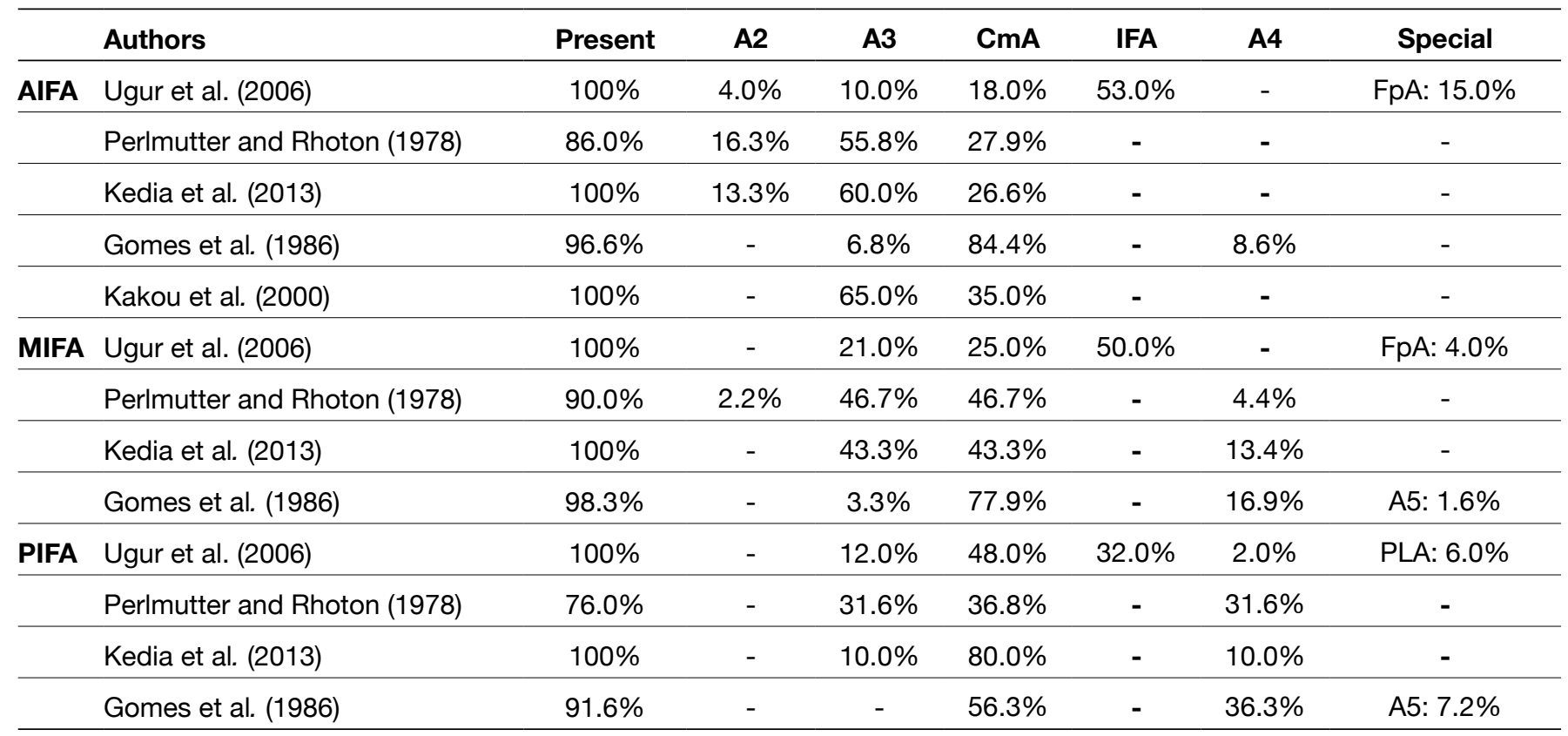


Table IV: The Origins of the Paracentral Lobule Artery and Internal Parietal Arteries (Superior and Inferior)

\begin{tabular}{|c|c|c|c|c|c|c|c|}
\hline & Authors & Present & A3 & $\mathrm{CmA}$ & A4 & A5 & Special: \\
\hline \multirow[t]{5}{*}{ PLA } & Ugur et al. (2006) & $100 \%$ & $12.0 \%$ & $66.0 \%$ & $18.0 \%$ & - & $\begin{array}{c}\text { Opposite A4: } 2.0 \% \\
\text { IFA: } 2.0 \%\end{array}$ \\
\hline & Perlmutter and Rhoton (1978) & $90.0 \%$ & $20.0 \%$ & $28.9 \%$ & $35.6 \%$ & $15.6 \%$ & - \\
\hline & Kedia et al. (2013) & $100 \%$ & - & $93.4 \%$ & $6.6 \%$ & - & - \\
\hline & Gomes et al. (1986) & $98.3 \%$ & - & $16.9 \%$ & $33.8 \%$ & $49.1 \%$ & - \\
\hline & Kakou et al. (2000) & - & $50.0 \%$ & $50.0 \%$ & - & - & - \\
\hline \multirow[t]{5}{*}{ SIPA } & Ugur et al. (2006) & $88.0 \%$ & $3.0 \%$ & $30.0 \%$ & $33.0 \%$ & $24.0 \%$ & PLA:10.0\% \\
\hline & Perlmutter and Rhoton (1978) & $78.0 \%$ & - & $23.1 \%$ & $12.8 \%$ & $64.1 \%$ & - \\
\hline & Kedia et al. (2013) & $93.0 \%$ & - & - & $80.0 \%$ & $20.0 \%$ & - \\
\hline & Gomes et al. (1986) & $85.0 \%$ & - & - & - & $100 \%$ & - \\
\hline & Kakou et al. (2000) & $100 \%$ & - & $15.0 \%$ & $35.0 \%$ & $50.0 \%$ & - \\
\hline \multirow[t]{5}{*}{ IIPA } & Ugur et al. (2006) & $85.0 \%$ & - & - & $10.0 \%$ & $75.0 \%$ & SIPA: $15.0 \%$ \\
\hline & Perlmutter and Rhoton (1978) & $64.0 \%$ & - & $3.1 \%$ & $16.6 \%$ & $81.3 \%$ & - \\
\hline & Kedia et al. (2013) & $60.0 \%$ & - & - & - & $100 \%$ & - \\
\hline & Gomes et al. (1986) & $60.0 \%$ & - & - & - & $100 \%$ & - \\
\hline & Kakou et al. (2000) & $67.0 \%$ & - & - & - & $100 \%$ & - \\
\hline
\end{tabular}

and therefore more studies need to be conducted on the length of these arteries. No triplication or other anomalies were observed in these specimens, which emphasizes the necessity for a large sample size to ensure that rare variation are observed.

\section{CONCLUSION}

The knowledge of the variations of the cerebral arteries is important to ensure that there are no complications during neurosurgery, surgical and endovascular interventions and it is essential for the treatment of cerebrovascular disease (6, $28,64,78)$. Aneurysms frequently occur at the branching of cerebral vessels and thus a thorough knowledge of the anatomy is important $(4,27,29,62)$. Information on the pattern of the cerebral arteries is important in interpretation of strokes and the obliteration of an arterial segment may cause unwanted or unexpected clinical consequences $(21,28)$.

\section{ACKNOWLEDGEMENT}

The authors would like to thank Mr. RP Williams for technical assistance.

\section{REFERENCES}

1. Avci E, Fossett D, Erdogan A, Egemen N, Attar A, Aslan M: Perforating branches of the anomalous anterior communicating complex. Clin Neurol Neurosurg 103(1):19-22, 2001
2. Bharatha A, Aviv RI, White J, Fox AJ, Symons SP: Intracranial arterial fenestrations: Frequency on CT angiography and association with other vascular lesions. Surg Radiol Anat 30(5): 397-401, 2008

3. Bradac GB: Cerebral Angiography- Normal Anatomy and Vascular Pathology. London: Springer, 2011: 47-56

4. Burbank NS, Morris PP: Unique anomalous origin of the left anterior cerebral artery. Am J Neuroradiol 26(10): 2533-2535, 2005

5. Canham PB, Finlay HM: Morphometry of medial gaps of human brain artery branches. Stroke 35(5):1153-1157, 2004

6. Cavalcanti DD, Albuquerque FC, Silva BF, Spetzler RF, Preul MC: The anatomy of the callosomarginal artery: Applications to microsurgery and endovascular surgery. Neurosurgery 66(3):602610, 2010

7. Choudhari KA: Fenestrated anterior cerebral artery. Br J Neurosurg 16(5):525-529, 2002

8. Cilliers K, Vorster W, Page BJ: The anatomical variation of the circle of Willis in a cadaver cohort representing the population dynamics of the Western Cape (Unpublished research report), Stellenbosch: Stellenbosch University, 2013

9. Cinnamon J, Zito J, Chalif DJ, Gorey MT, Black KS, Scuderi DM, Hyman RA: Aneurysm of the azygos pericallosal artery: Diagnosis by MR imaging and MR angiography. Am J Neuroradiol 13(1): 280-282, 1992

10. Critchley M: Syndromes of the anterior cerebral artery. Proc R Soc Med 23(5):630-632, 1930

11. Dimmick SJ, Faulder KC: Normal variants of the cerebral circulation at multidetector CT angiography. Radiographics 29(4): 1027-1043, 2009 
12. Dunker RO, Harris $A B$ : Surgical anatomy of the proximal anterior cerebral artery. J Neurosurg 44(3):359-367, 1976

13. Fawcett E, Blachford JV: The circle of Willis: An examination of 700 specimens. J Anat Physiol 40:63-70, 1905

14. Fisher CM: The circle of Willis: Anatomical variations. Vasc Dis 2: 99-105, 1965

15. Friedlander RM, Oglivy CS: Aneurysmal subarachnoid hemorrhage in a patient with bilateral A1 fenestrations associated with an azygos anterior cerebral artery. Case report and literature review. J Neurosurg 84(4): 681-684, 1996

16. Gailloud P, Albayram S, Fasel JH, Beauchamp NJ, Murphy KJ: Angiographic and embryologic considerations in five cases of middle cerebral artery fenestration. Am J Neuroradiol 23(4):585587, 2002

17. Gomes FB, Dujovny M, Umansky F, Berman SK, Diaz FG, Ausman $\mathrm{JI}$, Mirchandani HG, Ray WJ: Microanatomy of the anterior cerebral artery. Surg Neurol 26(2):129-141, 1986

18. Gunnal SA, Wabale RN, Farooqui MS: Variations of anterior cerebral artery in human cadavers. Neurology Asia 18(3):249-259, 2013

19. Hattori T, Kobayashi, H: Fenestration of the supraclinoid internal carotid artery associated with carotid bifurcation aneurysm. Surg Neurol 37(4):284-288, 1992

20. Huber P, Braun J, Hirschmann D, Agyeman JF: Incidence of berry aneurysms of the unpaired pericallosal artery: Angiographic study. Neuroradiology 19(3):143-147, 1980

21. Hussain Z, Corkill RA, Kuker W, Byrne JV: Distal aneurysms of the unpaired ACA: Embryologic and therapeutic aspects. Neuroradiology 47(3):209-214, 2005

22. Ito J, Washiyama K, Kim CH, Ibuchi Y: Fenestration of the anterior cerebral artery. Neuroradiology 21(5):277-280, 1981

23. Izci $Y$, Agrawal B, Ateş O, Başkaya MK: Superficial vascular anatomy of the medial prefrontal cortex: An anatomical study. Surg Neurol 72(4): 383-388, 2009

24. Jennings $S$, Haider A: Case report: The clinical significance of an azygos anterior cerebral artery. International Journal of Anatomical Variations 4:185-187, 2011

25. Jinkins JRL: Atlas of Neuroradiologic Embryology, Anatomy, and Variants. Lippincott Williams and Wilkins, 2000

26. Kahilogullari G, Comert A, Arslan M, Esmer AF, Tuccar E, Elhan A, Tubbs RS, Ugur HC: Callosal branches of the anterior cerebral artery: An anatomical report. Clin Anat 21(5):383-388, 2008

27. Kahilogullari G, Ugur HC, Comert A, Tekdemir I, Kanpolat Y: The branching pattern of the middle cerebral artery: Is the intermediate trunk real or not? An anatomical study correlating with simple angiography Laboratory investigation. J Neurosurg 116(5):10241034, 2012

28. Kakou M, Destrieux C, Velut S: Microanatomy of the pericallosal arterial complex. J Neurosurg 93:667-675, 2000

29. Kaplan HA: The lateral perforating branches of the anterior and middle cerebral arteries. J Neurosurg 23(3):305-310, 1965

30. Kapoor K, Singh B, Dewan LI: Variations in the configuration of the circle of Willis. Anat Sci Int 83(2):96-106, 2008

31. Kathuria S, Gregg L, Chen J, Gandhi D: Normal cerebral arterial development and variations. Semin Ultrasound CT MR 32(3): 242251, 2011

32. Katz RW, Horoupian DS, Zingesser L: Aneurysm of azygous anterior cerebral artery. A case report. J Neurosurg 48(5):804-808, 1978
33. Kayembe KN, Sasahara M, Hazama F: Cerebral aneurysms and variations in the circle of Willis. Stroke 15(5):846-850, 1984

34. Kedia S, Daisy S, Mukherjee KK, Salunke P, Srinivasa R, Narain MS: Microsurgical anatomy of the anterior cerebral artery in Indian cadavers. Neurol India 61(2):117-121, 2013

35. Kondo A, Koyama T, Ishikawa J, Iwaki K, Yamasaki T: Ruptured aneurysm of an azygos anterior cerebral artery. Neuroradiology 17(4):227-229, 1979

36. Krayenbuhl H, Yasargil MG, Huber P: Cerebral Angiography. Thieme Medical Publishers, 1982: 79-93

37. Kulenović A, Dilberović F, Ovcina F: Variation in the flow and branching of the anterior and middle cerebral arteries. Med Arh 57(1):3-5, 2003 (Abstract)

38. Kwak R, Niizuma H, Hatanaka M, Suzuki J: Anterior communicating artery aneurysms with associated anomalies. J Neurosurg 52(2): 162-164, 1980

39. Ladziński P, Maliszewski M, Majchrzak H: The accessory anterior cerebral artery: Case report and anatomic analysis of vascular anomaly. Surg Neurol 48(2):171-174, 1997

40. Ladziński P, Maliszewski M: Variability of the division of the cortical branches of the posterior cerebral artery. Anat Rec A Discov Mol Cell Evol Biol 282(1):74-82, 2005

41. Laitinen L, Snellman A: Aneurysms of the pericallosal artery. A study of 14 cases verified angiographically and treated mainly by direct surgical attack. J Neurosurg 17:447-458, 1960

42. Lehecka M, Dashti R, Hernesniemi J, Niemelä M, Koivisto T, Ronkainen A, Rinne J, Jääskeläinen $\mathrm{J}$ : Microneurosurgical management of aneurysms at the A2 segment of anterior cerebral artery (proximal pericallosal artery) and its frontobasal branches. Surg Neurol 70(3):232-246, 2008

43. Lemay M, Gooding CA: The clinical significance of the azygos anterior cerebral artery (ACA). Am J Roentgenol Radium Ther Nucl Med 98:602-610, 1966

44. Lemos VPJ: Frequency of the callosomarginal artery and proposal of a hypothesis with regard to its phylogenetic significance. Arq Neuropsiquiatr 42(4): 335-340, 1984

45. Macchi C, Catini C, Federico C, Gulisano M, Pacini P, Cecchi F, Corcos L, Brizzi E: Magnetic resonance angiographic evaluation of circulus arteriosus cerebri (circle of Willis): A morphologic study in 100 human healthy subjects. Ital J Anat Embryol 101(2):115123, 1996 (Abstract)

46. Makowicz G, Poniatowska R, Lusawa M: Variants of cerebral arteries - anterior circulation. Pol J Radiol 78(3):42-47, 2013

47. Marinković S, Milisavljević M, Marinković Z: Branches of the anterior communicating artery. Microsurgical anatomy. Acta Neurochir (Wien) 106(1-2):78-85, 1990 (Abstract)

48. Matsumura M, Nojiri K: Ruptured anterior communicating artery aneurysms associated with fenestration of the anterior cerebral artery. Surg Neurol 22(4):371-376, 1984

49. Milenković Z, Vucetić R, Puzić M: Asymmetry and anomalies of the circle of Willis in fetal brain. Microsurgical study and functional remarks. Surg Neurol 24(5):563-570, 1985

50. Minakawa T, Kawamata M, Hayano M, Kawakami K: Aneurysms associated with fenestrated anterior cerebral arteries. Report of four cases and review of the literature. Surg Neurol 24(3):284-288, 1985

51. Nathal E, Yasui N, Sampei T, Suzuki A: Intraoperative anatomical studies in patients with aneurysms of the anterior communicating artery complex. J Neurosurg 76(4):629-634, 1992 
52. Niederberger E, Gauvrit JY, Morandi X, Carsin-Nicol B, Gauthier T, Ferré JC: Anatomic variants of the anterior part of the cerebral arterial circle at multidetector computed tomography angiography. J Neuroradiol 37(3):139-147, 2010

53. Nordon DG, Rodrigues OFJ: Variations in the brain circulation the circle of Willis. J Morphol Sci 29(4):243-247, 2012

54. Nowinski WL, Thirunavuukarasuu A, Volkau I, Marchenko Y, Aminah B, Puspitasari F, Runge VM: A three-dimensional interactive atlas of cerebral arterial variants. Neuroinformatics 7(4):255-264, 2009

55. Nussbaum ES, Defillo A, Janjua TM, Nussbaum LA: Fenestration of the middle cerebral artery with an associated ruptured aneurysm. J Clin Neurosci 16(6):845-847, 2009

56. Ogawa A, Suzuki M, Sakurai Y, Yoshimoto T: Vascular anomalies associated with aneurysms of the anterior communicating artery: Microsurgical observations. J Neurosurg 72(5):706-709, 1990

57. Okahara M, Kiyosue H, Mori H, Tanoue S, Sainou M, Nagatomi H: Anatomic variations of the cerebral arteries and their embryology: A pictorial review. Eur Radiol 12(10):2548-2561, 2002

58. Osborn AG, Jacobs JM: Diagnostic Cerebral Angiography. $2^{\text {nd }} e d$. Lippincott Williams and Wilkins, 1999: 117-133

59. Ozaki T, Handa H, Tomimoto K, Hazama F: Anatomical variations of the arterial system of the base of the brain. Arch Jpn Chir 46: 3-17, 1977

60. Parmar $\mathrm{H}$, Sitoh YY, Hui F: Normal variants of the intracranial circulation demonstrated by MR angiography at 3T. Eur J Radiol 56(2):220-228, 2005

61. Pekcevik Y, Hasbay E, Oncel D: Colloid cyst of the third ventricle associated with anterior cerebral artery trifurcation and agenesis of the corpus callosum: Findings on MRI and CT angiography. Pediatr Radiol 42(9):1130-1133, 2012

62. Perlmutter D, Rhoton AL: Microsurgical anatomy of the distal anterior cerebral artery. J Neurosurg 49:204-228, 1978

63. Ramos A, Chaddad-Neto F, Joaquim AF, Campos-Filho JM, Mattos JP, Ribas GC, Oliveira ED: The microsurgical anatomy of the gyrus rectus area and its neurosurgical implications. Arq Neuropsiquiatr 67(1):90-95, 2009

64. Ring BA, Waddington MM: Roentgenographic anatomy of the pericallosal arteries. Am J Roentgenol Radium Ther Nucl Med 104:109-118, 1968

65. Saidi H, Kitunguu PK, Ogeng'O JA: Variant anatomy of the anterior cerebral artery in adult brains. Afr J Neurol Sci 27(1):97-105, 2008

66. Sanders WP, Sorek PA, Mehta BA: Fenestration of intracranial arteries with special attention to associated aneurysms and other anomalies. Am J Neuroradiol 14(3):675-680, 1993 (Abstract)

67. Serizawa T, Saeki N, Yamaura A: Microsurgical anatomy and clinical significance of the anterior communicating artery and its perforating branches. Neurosurgery 40(6):1211-1216, 1997

68. Stefani MA, Schneider FL, Marrone ACH, Severino AG, Jackowski AP, Wallace MC: Anatomic variations of anterior cerebral artery cortical branches. Clin Anat 13:231-236, 2000
69. Stefani MA, Schneider FL, Marrone ACH, Severino AG: Influensce of the gender on cerebral vascular diameters observed during the magnetic resonance angiographic examination of Willis circle. Braz Arch Biol Technol 56(1):45-52, 2013

70. Szdzuy D, Lehmann R, Nickel B: Common trunk of the anterior cerebral arteries. Neuroradiology 4(1):51-56, 1972

71. Tao X, Yu XJ, Bhattarai B, Li TH, Jin H, Wei GW, Ming JS, Ren $\mathrm{W}$, Jiong C: Microsurgical anatomy of the anterior communicating artery complex in adult Chinese heads. Surg Neurol 65(2):155161, 2006

72. Teal JS, Rumbaugh CL, Bergeron RT, Segall HD: Angiographic demonstration of fenestrations of the intradural intracranial arteries. Radiology 106(1):123-126, 1973

73. Topsakal C, Ozveren MF, Erol FS, Cihangiroglu M, Cetin H: Giant aneurysm of the azygos pericallosal artery: Case report and review of the literature. Surg Neurol 60(6):524-533, 2003

74. Tulleken CA: A study of the anatomy of the anterior communicating artery with the aid of the operating microscope. Clin Neurol Neurosurg 80(3):169-173, 1978

75. Türe U, Yaşargil MG, Krisht AF: The arteries of the corpus callosum: A microsurgical anatomic study. Neurosurgery 39(6): 1075-1084, 1996

76. Uchino A, Nomiyama K, Takase Y, Kudo S: Anterior cerebral artery variations detected by MR angiography. Neuroradiology 48(9): 647-652, 2006

77. Uchino A, Takase Y, Nomiyama K, Egashira R, Kudo S: Fenestration of the middle cerebral artery detected by MR angiography. Magn Reson Med Sci 5(1):51-55, 2006

78. Ugur HC, Kahilogullari G, Esmer AF, Combert A, Kanpolat Y: A neurosurgical view of anatomical variations of the distal anterior cerebral artery: An anatomical study. J Neurosurg 104:1-7, 2006

79. Vasović L, Trandafilović M, Vlajković S, Jovanović I, Ugrenović S: Anterior cerebral-anterior communicating complex in the postnatal period: From a fenestration to the multiplication of arteries. Medicine and Biology 16(1):1-11, 2014

80. Vasović LP: Fetal azygos pericallosal artery. Clin Anat 19(4): $327-$ 331, 2006

81. Vucetic RR: Segmental duplication of the fetal anterior cerebral artery. J Anat 192(3):431-434, 1998

82. Wan-Yin S, Ming-Hua L, Bin-Xian G, Yong-Dong L, Hua-Qiao T: Azygous anterior cerebral artery and associated aneurysms: Detection and identification using 3-dimensional time-of-flight magnetic resonance angiography. J Neuroimaging 24(1):18-22, 2014

83. Windle BC: The arteries forming the Circle of Willis. J Anat Physio 22(2):289-293, 1888

84. Yamada T, Inagawa T, Takeda T: Ruptured aneurysm at the anterior cerebral artery fenestration. Case report. J Neurosurg 57(6): 826828, 1982

85. Zurada A, Gielecki J, Tubbs RS, Loukas M, Cohen-Gadol AA, Chlebiej M, Maksymowicz W, Nowak D, Zawiliński J, Michalak $\mathrm{M}$ : Three-dimensional morphometry of the A2 segment of the anterior cerebral artery with neurosurgical relevance. Clin Anat 23(7):759-769, 2010 